\title{
Growth conditions modify the concentrations of bioactive caffeic acid derivatives, amino acids and the structure of Plantago leaves
}

\author{
Mary T. KELLY ${ }^{1}$, Anne Mette LYKKE ${ }^{2 *}$, Laurence MONDOLOT ${ }^{3}$ and \\ Helle Weber RAVN ${ }^{2}$ \\ ${ }^{1}$ UMR 1083, 'Sciences pour Oenologie', University of Montpellier, Faculty of Pharmacy, \\ 15 Avenue Charles-Flahault, F-34093 Montpellier Cedex 5, France. \\ ${ }^{2}$ Department of Bioscience, Aarhus University, Vejlsфvej 25, DK-8600 Silkeborg, Denmark. \\ ${ }^{3}$ UMR 5175 CEFE-CNRS, University of Montpellier, Faculty of Pharmacy, \\ 15 Avenue Charles-Flahault, F-34093 Montpellier Cedex 5, France. \\ *Corresponding author; E-mail: aml@bios.au.dk, Tel: +453078371
}

\begin{abstract}
Plantago species are widely used in natural medicine, but the effect of growth conditions on the chemical content of leaves is poorly understood. Three species of Plantago and three varieties of Plantago major L. were grown in greenhouse and outdoors to investigate effects on the content and composition of three bioactive caffeic acid derivatives (BCAD) (plantamajoside, iso-plantamajoside and verbascoside), free amino acids (FAA) and leaf texture of the plants. High Performance Thin Layer Chromatography (HPTLC) was used for the quantification of the BCAD, amino acids were determined by High Performance Liquid Chromatography (HPLC) and a histochemical technique was used to study the physical structure of the plants. Plants grown outdoors were significantly richer in BCAD compared with greenhouse grown plants. The highest content was seen in outdoor grown Plantago major L. (45.15 $\pm 4.36 \mathrm{mg} / \mathrm{g} \mathrm{DW})$ and the lowest in greenhouse grown Plantago major 'Frills' $(7.74 \pm 0.96 \mathrm{mg} / \mathrm{g} \mathrm{DW})$. Conversely, amino acid concentrations were significantly greater for greenhouse grown plants compared with outdoor grown plants. The highest concentration was found in greenhouse grown P. major L. and Plantago major 'Rubrifolia' ( $8.66 \pm 0.64 \mathrm{mg} / \mathrm{g}$ DW and $7.94 \pm 0.97 \mathrm{mg} / \mathrm{g} \mathrm{DW}$, respectively), whereas the lowest was in Plantago lanceolata L. grown outdoors $(0.73 \pm 0.09 \mathrm{mg} / \mathrm{g} \mathrm{DW})$. The leaf texture of the plants grown outdoors and in the greenhouse was significantly different. This study underlines the importance of environmental and growing conditions for plants in order to obtain high concentrations of bioactive compounds either from a nutritional point of view or for use in natural medicine.
\end{abstract}

(C) 2018 International Formulae Group. All rights reserved.

Keywords: Biochemical analysis, histochemistry, HPLC, HPTLC, plantamajoside, verbascoside.

\section{INTRODUCTION}

The Plantago-genus represents about 275 species in the Plantaginaceae family (Ravn et al., 2015). Plantago species have worldwide distribution and are widely used in natural medicine (Jdey et al., 2017; Ogbiko et al., 2018). They are often employed in the treatment of diseases related to the skin, respiratory, reproductive and digestive organs and against inflammations and infections (Ravn et al., 2015). Plantago major L. and $P$. asiatica L. have strong market demands in 
Asia and P. major is emerging as a medicinal crop in horticulture in Europe. The aerial parts of $P$. asiatica L. are used as the crude drug 'Plantago Herba' (Shazenso) in China, Korea and Japan (Kyokai, 1986).

The major active constituents of these medicinal plants are the bioactive caffeic acid derivatives (BCAD) plantamajoside, isoplantamajoside and verbascoside, which are important antioxidants (Amakura et al., 2012; Ravn et al., 2015; Jdey et al., 2017). The aerial parts of Plantago media L., P. major, $P$. lanceolata L., Plantago depressa (Willd.) and $P$. asiatica have been analyzed for the content of plantamajoside and verbascoside (Olennikov et al., 2011; Gonda et al., 2013). Bioactive plant components are well known from many plant species (Byamukama et al., 2015; Ogwuche et al., 2015; Adagba et al., 2017; Sawadogo et al., 2017).

Unlike BACD, there are little data on the free amino acid content of Plantago species. The few reported studies relate to individual species, such as $P$. major (Mohamed et al., 2011), Plantago ovata Forssk. (Romero-Baranzini et al., 2006), P. lanceolata (Grange and West, 1994) and Plantago japonica Franch. \& Sav. (Sagisaka et al., 1988).

This aim of this study was to conduct a comparative investigation of three BCAD (plantamajoside, iso-plantamajoside and verbascoside), free amino acid composition and physical structure as biomarkers in three species and three selected varieties of Plantago grown under greenhouse contra outdoor environmental conditions, in order to verify the importance of environmental conditions for the content and composition of the plants.

\section{MATERIALS AND METHODS}

\section{Plant and soil material}

Seeds of $P$. major, $P$. media, $P$. lanceolata were obtained from HerbiSeed, Twyford, UK and the varieties $P$. major 'Frills', P. major 'Rosularis' and P. major 'Rubrifolia' were obtained from Plant World Seeds, Devon, UK. The seeds were sown in a greenhouse on April 10 2013. On May14 2013 half of the plants were placed outdoors until June 24 2013, when all the leaves of the plants were harvested and stored at $-20{ }^{\circ} \mathrm{C}$ until freeze-drying. The soil used for cultivation both in the greenhouse and outdoors was $2 / 3$ professional substrate, Kekkilä Brown 525W, Kekkilä Garden, Garta, Odense, Denmark (Brown sphagnum peat H2von post, $5-25 \mathrm{~mm}$, Addition: $1.0 \mathrm{~kg} / \mathrm{m}^{3} \mathrm{~N}$ $\mathrm{P}_{2} \mathrm{O}_{5}-\mathrm{K}_{2} \mathrm{O}$ 14-16-18+TE, Dolomite limestone wetting agent, $\mathrm{pH}=5.5-5.6$ and $1 / 3$ ordinary beach sand. The plants were watered regularly until harvest.

\section{Standards and identification of plantamajoside, iso-plantamajoside and verbascoside}

Standards of plantamajoside and verbascoside (Figure 1) were isolated from $P$. major subsp. pleiosperma according to a previously published protocol (Ravn et al., 1988) and plantamajoside used as standard for the quantification of iso-plantamajoside. Identification of the three compounds was optimised using different HPTLC plates, eluents and reagents to enhance UV detection and colour reactions (Ravn et al., 1988).

\section{Sample preparation for BACD}

Leaves (six replicates) from the different Plantago species and varieties were placed in individual paper bags and lyophilized. The plant material was crushed and $6 \times 50.00 \mathrm{mg}$ greenhouse plants and $6 \mathrm{x}$ $25.00 \mathrm{mg}$ outdoor plants per $\mathrm{ml}$ of $80 \%$ ethanol/water were extracted in an ultrasonic bath for two hours. The temperature in the ultra-sonic bath was maintained at less than 40 ${ }^{\circ} \mathrm{C}$ during the extraction to avoid decomposition of the BCAD. The samples were filtered through a Whatman filter GMF w/GMF $0.45 \mu \mathrm{m}$ and analysed by for HPTLC.

\section{HPTLC analysis of BACD}

The analysis was performed using HPTLC-plates with silicagel 60 (Merck $1.005547 .0001)(20 \times 10 \mathrm{~cm})$. The application volume was $5 \mu \mathrm{l}$ of both extracts and standards. Samples were added to the plates as a band of $10 \mathrm{~mm}$ using an ATS-4 CAMAG applicator. Fresh eluent was prepared daily, consisting of ethyl acetate: $40 \%$ formic acid 
(2:1). The development time was $56.4 \pm 1.4$ $\min (\mathrm{N}=18)$. The plates were air-dried and BCAD were detected under UV light at 366 $\mathrm{nm}$ using auto-fluorescence of the compounds. They were also detected using $1 \%$ diphenylboric acid-2-aminoethyl ester (Fluka) in 5\% polyethyleneglycol 4000 $\left(\mathrm{PEG}_{4000}\right)$ in $96 \%$ ethanol (366 nm under UVlight). The equipment used for the analysis was from CAMAG (Muttenz, Switzerland) and comprised an ATS-4 applicator and a Reprostar 3 cabinet with DXA 252 camera (lens Computar, focal length $16 \mathrm{~mm}$, aperture f4.0). Camag software, WinCats (version 1.4.2.8121) and VideoScan (version 1.01.00) were used to analyse the digital images obtained from the photographs of the HPTLC plates with both extracts and the standard solutions on each plate.

\section{Sample preparation for amino acids}

For each repetition, $50 \mathrm{mg}$ of each lyophilized sample were weighed in preweighed $2 \mathrm{ml}$ Eppendorf tubes and stored at $20{ }^{\circ} \mathrm{C}$ until analysis. A previously optimized (Hjorth, et al., 2006) extraction method was used: 1 or $1.20 \mathrm{ml}$ (depending on the volume of the lyophilisate) of $10 \%(\mathrm{v} / \mathrm{v})$ ethanol in water was added to the tubes and the amino acids were extracted for two hours in an ultrasonic bath. Ice packs were added to the bath to ensure that the temperature remained below $40^{\circ}$. The samples were then diluted 5fold with freshly distilled water for further analysis.

\section{HPLC analysis of amino acids}

Samples were analysed according to a previously published method (Kelly and Larroque, 2010) with some modifications. Specifically, mobile phase A contained $2.5 \%$ acetonitrile and $1 \%$ tetrahydrofuran in $0.05 \mathrm{M}$ acetate buffer ( $\mathrm{pH}$ 6.5) and mobile phase B consisted of acetonitrile: methanol [1:1] to obtain complete separation of the critical pair histidine and glycine. The in-house $o$ phthaldialdehyde (OPA) reagent solution used in the previous paper was replaced by a proprietary $o$-phthaldialdehyde- mercaptoethanol solution (PN 5061-3335) obtained from Agilent (Agilent Technologies Massy, France). Gradient and derivatisation conditions and the method of quantification were as previously described.

\section{Histochemical technique}

For each lyophilized sample, a 4-6 mm portion of the leaf center was used from six replicate plants. They were embedded in 3\% agarose (type II EEO, Panreac) before cutting for histochemical examination. Transverse sections $(40 \mu \mathrm{m})$ were obtained using a Leica VT 1000S vibrating blade microtome (frequency 7, speed 2). For auto-fluorescence observation, transverse sections were mounted in distilled water without any reagent. Transverse sections of specimens were viewed under a light microscope (Nikon Optiphot) with UV light (filter UV-1A: $365 \mathrm{~nm}$ excitation filter). Leaf transverse sections were then observed after treatment with a specific reagent that enhanced the fluorescence of the BCAD, containing $0.25 \%$ diphenylboric acid-2-aminoethyl ester (DPBA) and $0.02 \%$ Triton-X-100 (v/v). The leaf sections were placed on a microscope slide and $5 \mu 1$ of the DPBA-solution was distributed evenly on each. Under these conditions, BCAD were visible as a greenishwhite fluorescence (Mondolot-Cosson et al., 1997). Photographs were taken with a digital Nikon Coolpix 4500 camera.

\section{Statistical analysis}

All data were reported as means \pm standard deviations of six replicates for each treatment. Statistical analysis was performed using ANOVA in order to test for differences in content of plantamajoside, isoplantamajoside, verbascoside, total content of BCAD and amino acids between plants grown outdoors and in the greenhouse. Principal component analysis (PCA) was based on a matrix with six species/varieties and their content of the compounds. The PCA was based on correlations among variables in order to place equal weight on the variables included in the analysis. 
<smiles>O=C(/C=C/c1ccc(O)c(O)c1)O[C@H]1[C@@H](CO)O[C@H](OCCc2ccc(O)c(O)c2)[C@@H](O)[C@H]1O[C@@H]1O[C@H](CO)[C@@H](O)[C@H](O)[C@H]1O</smiles><smiles>C[C@H]1O[C@H](O[C@@H]2[C@@H](OC(=O)/C=C/c3ccc(O)c(O)c3)[C@H](CO)O[C@@H](OCCc3ccc(O)c(O)c3)[C@H]2O)[C@H](O)[C@@H](O)[C@@H]1O</smiles>

Figure 1: Chemical structure of a) plantamajoside (3,4-dihydroxy- $\beta$-phenethyl-O- $\beta$-Dglucopyranosyl-( $(1 \rightarrow 3)-4-O-$ caffeoyl- $\beta$-D-glucopyranoside $) \quad$ and $\quad$ b) verbascoside $\quad(3,4-$ dihydroxyphenyl)ethyl 3-O-(6-deoxy-a-L-mannopyranosyl)- $\beta$-D-glucopyranoside).

\section{RESULTS}

Plantamajoside, iso-plantamajoside and verbascoside

The location and separation of the BCAD (plantamajoside, iso-plantamajoside and verbascoside) on the HPTLC-plates were indicated as Rf-values (Table 1). The content and composition of the BCAD were significantly different between plants grown in the greenhouse and outdoors (Table 2). The content of plantamajoside, iso-plantamajoside and verbascoside were, in most cases, higher in the outdoor grown plants compared with the greenhouse grown plants. Overall, the total content of BCAD was two- to four- times greater for plants grown outdoors compared with plants grown in the greenhouse.

The differences in the total content of BCAD in the different species were minor compared with differences produced by growth conditions: $P$. major had the highest content of iso-plantamajoside, whereas $P$. 
lanceolata and $P$. media had the highest concentrations of verbascoside, for both greenhouse and outdoor grown plants. The total content of BCAD between the varieties P. major 'Rosularis', P. major 'Rubrifolia' was almost identical whereas the total content in P. major 'Frills' was significantly lower. $P$. major 'Rosularis' and P. major 'Rubrifolia' mainly contained plantamajoside whereas $P$. major 'Frills' principally contained verbascoside for both greenhouse grown and outdoors.

The highest content of plantamajoside was found in $P$. major 'Rosularis' and $P$. major 'Rubrifolia' grown outdoors (36.54 \pm $4.90 \mathrm{mg} / \mathrm{g}$ DW and $34.88 \pm 5.04 \mathrm{mg} / \mathrm{g}$ DW, respectively) and lowest for $P$. media $(0.21 \pm$ $0.25 \mathrm{mg} / \mathrm{g}$ DW for the plants grown in the greenhouse and $0.33 \pm 0.44 \mathrm{mg} / \mathrm{g}$ DW for the plants grown outdoors). The highest content of iso-plantamajoside was observed in $P$. major grown outdoors $(21.01 \pm 3.19 \mathrm{mg} / \mathrm{g}$ DW) and lowest for P. major 'Rosularis' grown in the greenhouse $(0.22 \pm 0.22 \mathrm{mg} / \mathrm{g}$ DW). Iso-plantamajoside was not found in $P$. lanceolata, P. media and P. major 'Frills', neither in plants grown in greenhouse nor outdoors. The highest content of verbascoside was detected in P. lanceolata and P. media grown outdoors $(38.79 \pm 10.53 \mathrm{mg} / \mathrm{g}$ DW and $34.95 \pm 9.36 \mathrm{mg} / \mathrm{g}$ DW, respectively) and the lowest in P. major 'Rubrifolia' and P. major 'Rosularis' (not detected in both plants grown in the greenhouse $)$ and $(0.07 \pm 0.18 \mathrm{mg} / \mathrm{g} \mathrm{DW}$ and $0.07 \pm 0.17 \mathrm{mg} / \mathrm{g}$ DW for the plants grown outdoors). The highest total content of all three BCAD was found in $P$. major and $P$. lanceolata $(45.15 \pm 2.55 \mathrm{mg} / \mathrm{g} \mathrm{DW}$ and 40.31 $\pm 9.91 \mathrm{mg} / \mathrm{g} \mathrm{DW}$, respectively, for the plants grown outdoors) and lowest for $P$. major 'Frills' grown in the greenhouse (7.74 \pm 0.96 $\mathrm{mg} / \mathrm{g}$ DW).

Histochemical analysis confirmed HPTLC results: Higher BCAD concentrations were observed for the plants grown outdoors compared with those grown in the greenhouse. Interestingly, the mesophyll in the outdoor grown plants was more dense and homogenous than that of the plants grown in greenhouse, and the BCAD were distributed in both the palisade and spongy parenchyma (Figure 2). This was particularly obvious in $P$. major where the highest content of BCAD was detected (Figure 2a). In $P$. major 'Rubrifolia', this was also visible at greater magnification (Figure 2b). The BCAD were almost exclusively confined to the palisade parenchyma in greenhouse grown plants (Figure 2a(ii) and 2b(ii)), whereas these compounds were present in the entire mesophyll in outdoor grown plants (Figure $2 a(i)$ and $2 b(i))$.

\section{Free amino acids}

The FAA and the biogenic amines, histamine and tyramine were determined High Performance Liquid Chromatography (HPLC). The total FAA content was greater in greenhouse grown plants (Figure 3) and interestingly, histamine was more abundant in outdoor grown plants. There were statistically significant differences both among species and varieties and between plants grown outdoors and in greenhouse. Amongst the outdoor grown plants, $P$. major was the richest in most FAA with $8.66 \pm 0.64 \mathrm{mg} / \mathrm{g}$ DW, whereas $P$. media had the lowest content with $3.36 \pm 0.57 \mathrm{mg} / \mathrm{g}$ DW (Table 3). Aspartate was the most abundant amino acid in the majority of plants with a concentration of $5.40 \pm 0.87 \mathrm{mg} / \mathrm{g}$ DW. The total content of glutamine at $6.25 \pm 0.62 \mathrm{mg} / \mathrm{g}$ was skewed by the fact that $P$. major 'Rubrifolia' was remarkably rich in this compound $(2.70 \pm 0.23$ $\mathrm{mg} / \mathrm{g} \mathrm{DW}$ ), whereas concentrations varied from $0.31 \pm 0.07 \mathrm{mg} / \mathrm{g}$ DW for $P$. media to $1.26 \pm 0.11 \mathrm{mg} / \mathrm{g}$ DW for $P$. major. Other predominant amino acids were, in order of decreasing abundance: alanine, glutamate, GABA, glutamine, serine and asparagine.

The PCA of the amino acid concentrations showed a clear distinction among species and varieties and illustrated that the content was higher in greenhouse grown plants (Figure 4). The fi rst axis describing $59 \%$ of the variation showed a clear separation among the species. The content of the individual FAA were positively correlated with the first axis, which demonstrates that some species notably $P$. 
major and $P$. major 'Rubrifolia' were particularly rich in amino acids, whereas concentrations in P. lanceolata and P. media, were relatively low. P. major 'Frills' had high concentrations of glutamate and aspartate when grown in the greenhouse, which was expressed on the second axis explaining $12 \%$ of the variation.

Table1: Rf-values of bioactive caffeic acid derivatives: plantamajoside, iso-plantamajoside and verbascoside as standards or in extracts.

\begin{tabular}{lccc}
\hline Compound name & In extract/standard & Rf-values & Number of replicates \\
\hline Plantamajoside & standard & $0.63 \pm 0.03$ & 39 \\
Plantamajoside & In extract & $0.62 \pm 0.03$ & 125 \\
Iso- plantamajoside & In extract & $0.67 \pm 0.02$ & 54 \\
Verbascoside & standard & $0.78 \pm 0.02$ & 39 \\
Verbascoside & In extract & $0.78 \pm 0.02$ & 106 \\
\hline
\end{tabular}

HPTLC-analysis, development time: $56.4 \mathrm{~min} \pm 1.4 \mathrm{~min}, \mathrm{~N}=18$.

Table 2: Bioactive cafeic acid derivatives (mg/g DW) in Plantago species.

\begin{tabular}{|c|c|c|c|c|c|}
\hline Species/varieties & $\begin{array}{l}\text { Growth } \\
\text { condition }\end{array}$ & Plantamajoside & Iso-plantamajoside & Verbascoside & Total \\
\hline P. major & Greenhouse & $4.33 \pm 0.52$ & $12.12 \pm 1.86$ & $3.65 \pm 0.71$ & $20.10 \pm 2.55$ \\
\hline P. major & Outdoors & $14.82 \pm 0.78$ & $21.01 \pm 3.19$ & $9.32 \pm 1.15$ & $45.15 \pm 4.36$ \\
\hline P. major 'Rubrifolia' & Greenhouse & $8.60 \pm 1.98$ & $0.63 \pm 0.55$ & $0.00 \pm 0.00$ & $9.23 \pm 2.32$ \\
\hline P. major 'Rubrifolia' & Outdoors & $34.88 \pm 5.04$ & $1.25 \pm 1.02$ & $0.07 \pm 0.18$ & $36.20 \pm 8.98$ \\
\hline P. major 'Rosularis' & Greenhouse & $11.45 \pm 2.23$ & $0.22 \pm 0.22$ & $0.00 \pm 0.00$ & $11.67 \pm 2.15$ \\
\hline P. major 'Rosularis' & Outdoors & $36.54 \pm 4.90$ & $1.00 \pm 0.92$ & $0.07 \pm 0.17$ & $37.61 \pm 9.14$ \\
\hline P. lanceolata & Greenhouse & $0.42 \pm 0.30$ & $0.00 \pm 0.00$ & $9.96 \pm 1.09$ & $10.38 \pm 1.09$ \\
\hline P. lanceolata & Outdoors & $1.52 \pm 0.81$ & $0.00 \pm 0.00$ & $38.79 \pm 10.53$ & $40.31 \pm 9.91$ \\
\hline P. media & Greenhouse & $0.21 \pm 0.25$ & $0.00 \pm 0.00$ & $10.26 \pm 1.44$ & $10.47 \pm 1.47$ \\
\hline P. media & Outdoors & $0.33 \pm 0.41$ & $0.00 \pm 0.00$ & $34.95 \pm 9.36$ & $35.28 \pm 9.12$ \\
\hline P. major 'Frills' & Greenhouse & $0.35 \pm 0.34$ & $0.00 \pm 0.00$ & $7.39 \pm 0.82$ & $7.74 \pm 0.96$ \\
\hline P. major 'Frills' & Outdoors & $0.35 \pm 0.46$ & $0.00 \pm 0.00$ & $25.04 \pm 5.82$ & $25.39 \pm 5.59$ \\
\hline
\end{tabular}

Values are means \pm SD of replicates, values in italics are significantly different. 

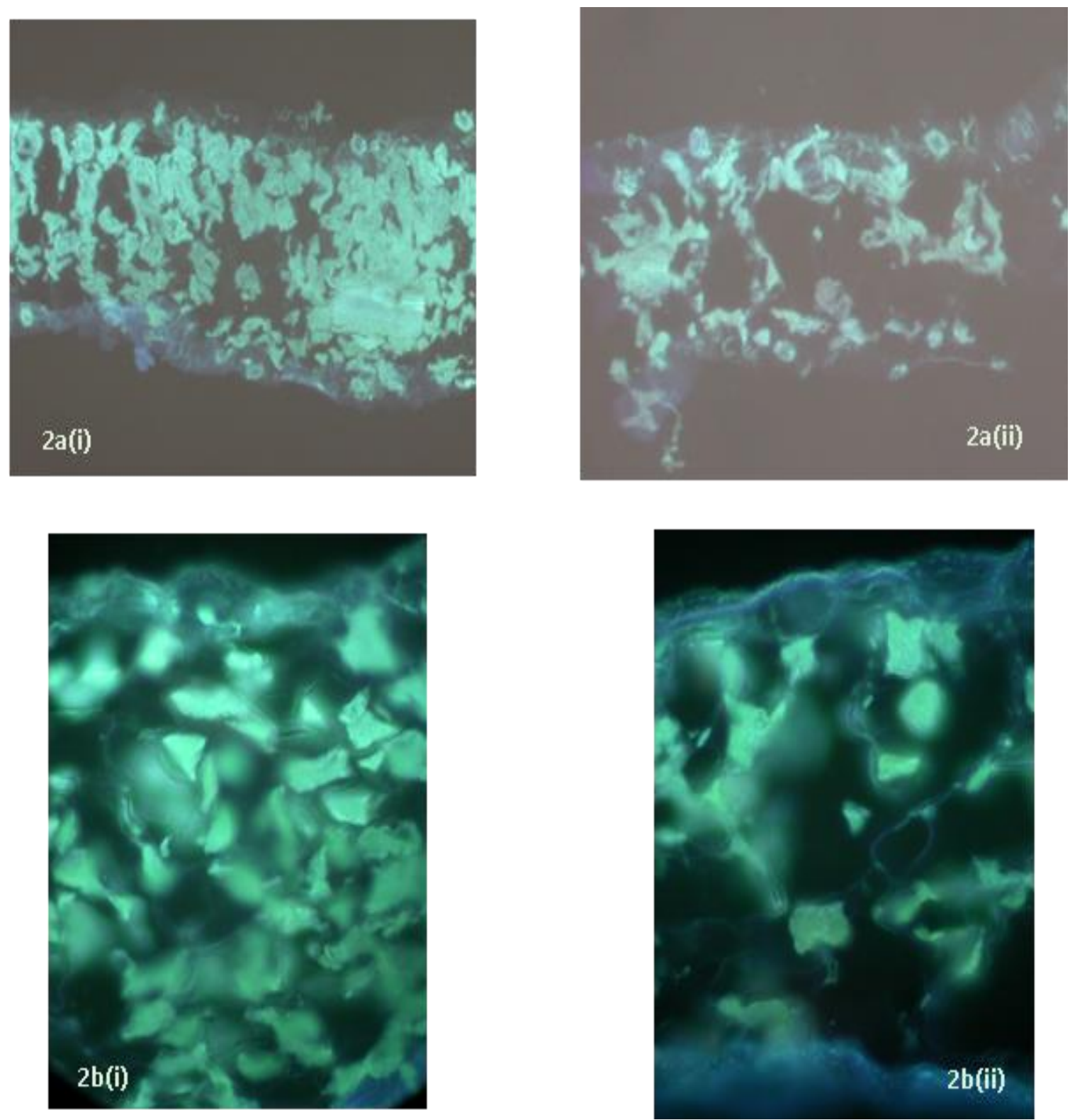

Figure 2: Histochemical analysis of Plantago leafs from plants cultivated in greenhouse and outdoors. 2a(i): P. major x 100, outdoors. 2a(ii) P. major, x 100, greenhouse. 2b(i): P. major 'Rubrifolia' x 400, outdoors. $2 \mathrm{~b}$ (ii): $P$. major 'Rubrifolia' $\mathrm{x} 400$, greenhouse. The greenish-white fluorescence of bioactive caffeic acid derivatives in the outdoor grown plants was more intense and present in almost all mesophyll cells compared to the plants grown in the greenhouse, in which the cells were also more dispersed. At this magnification, it can be observed that in the indoor grown plants the fluorescence was only present in some palisade parenchyma cells. In the plants grown outdoors the bioactive caffeic acid derivatives were present in high concentrations and present in almost all mesophyll cells. 


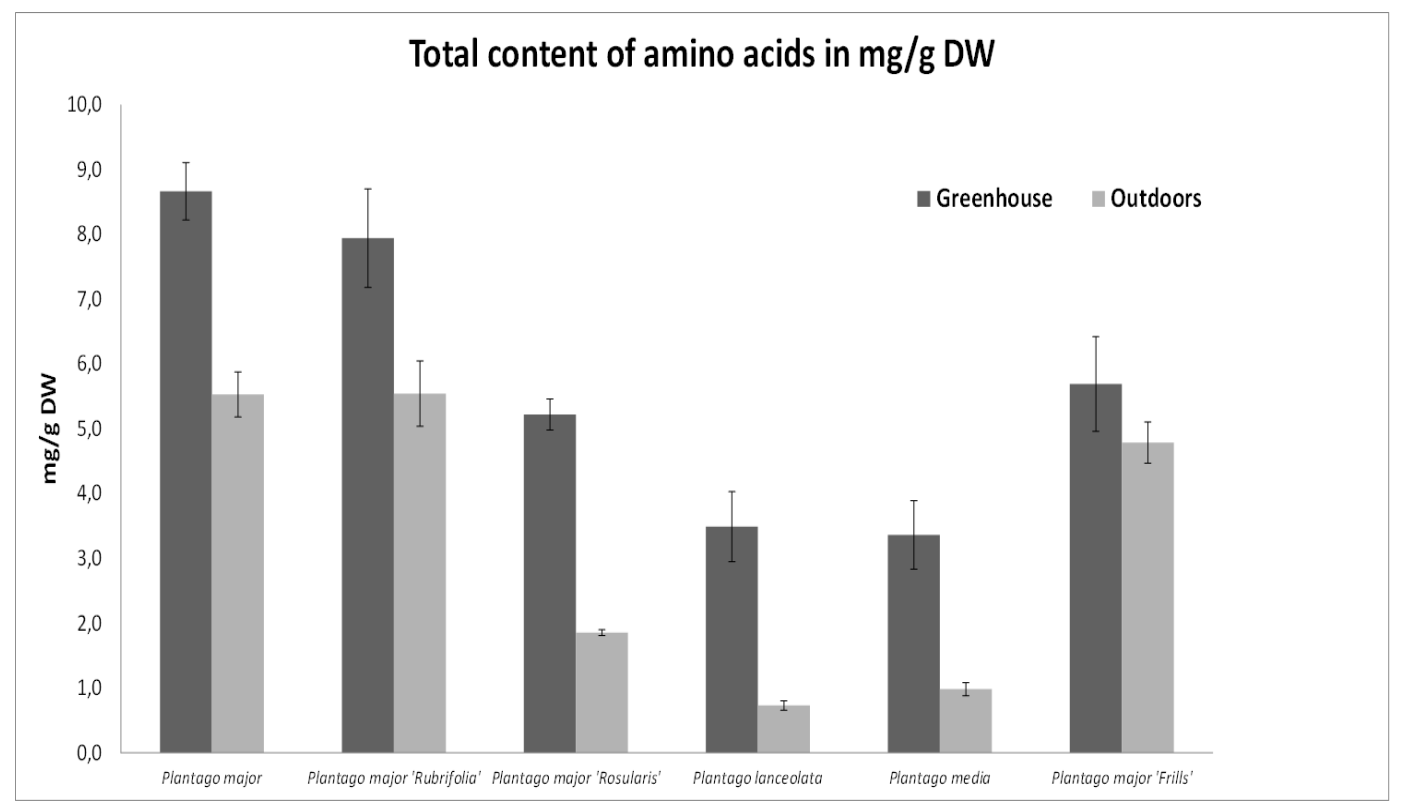

Figure 3: Total content of free amino acids in $\mathrm{mg} / \mathrm{g}$ dry weight in plants grown in the greenhouse (dark grey) and outdoors (light grey).
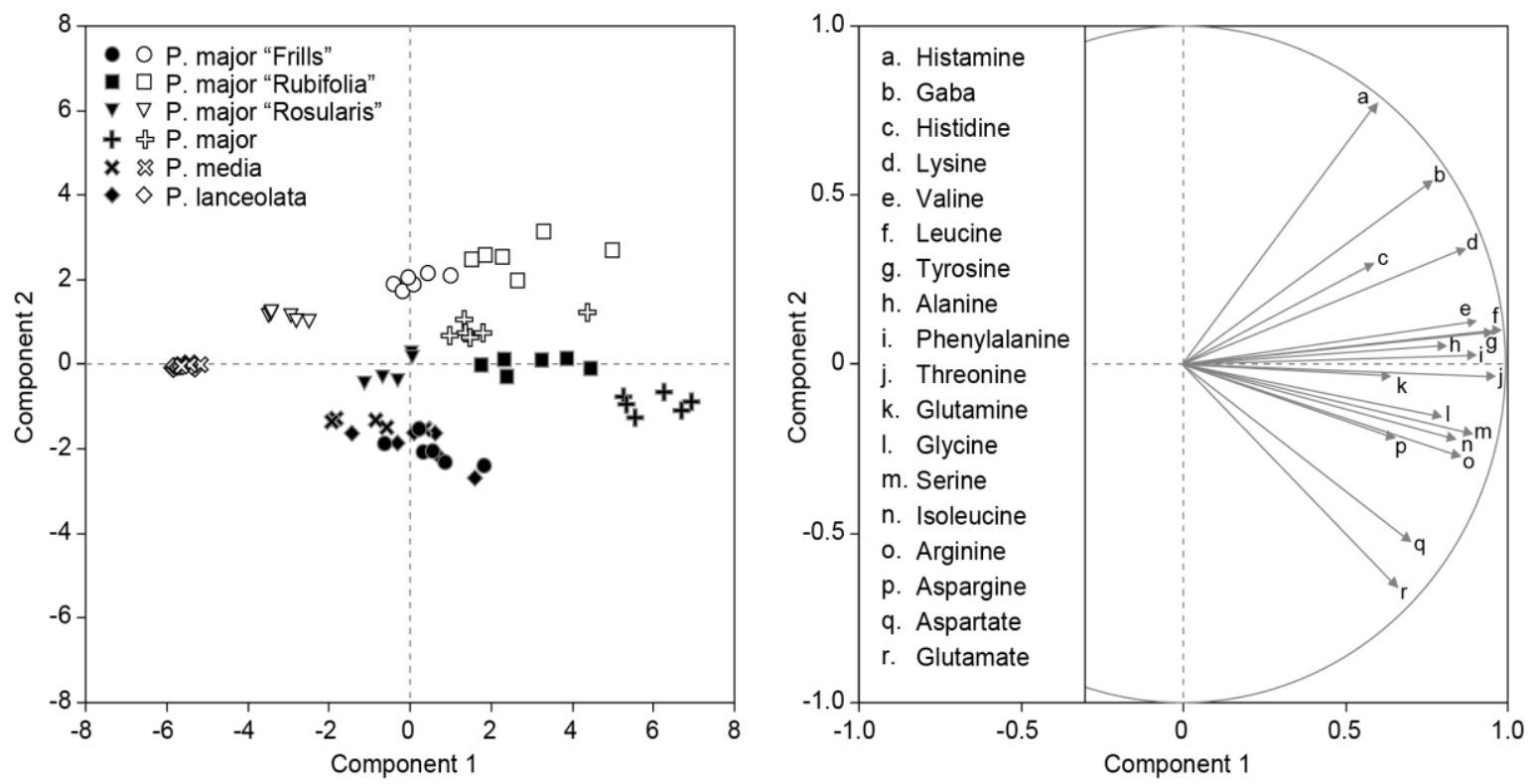

Figure 4: PCA diagram of total amino acid content of six Plantago species/varities grown in greenhouse (open signatures) and outdoors (filled signatures). Ala: alanine, Arg: arginine, Asn: asparagine, Asp: aspartate, GABA: gamma-aminobutyric acid, Glm: glutamine, Glu: glutamate, Gly: glycine, Him: histamine, His: histidine, Ile: isoleucine, Leu: leucine, Lys: lysine, Phe: phenylalanine, Ser: serine, Thr: threonine, Tyr: tyrosine, Val: valine. 
M. T. KELLY et al. / Int. J. Biol. Chem. Sci. 12(5): 2244-2257, 2018

Table 3: Content of free amino acids, histamine in Plantago grown in greenhouseand outdoors.

\begin{tabular}{|c|c|c|c|c|c|c|c|c|c|c|c|c|}
\hline Species/varieties & $\begin{array}{l}\text { Growth } \\
\text { conditions }\end{array}$ & Asp & Glu & Asn & Ser & Glm & His & Gly & Thr & Arg & Ala & \\
\hline P. major & Greenhouse & $1.04 \pm 0.06$ & $0.71 \pm 0.03$ & $1.07 \pm 0.17$ & $0.90 \pm 0.03$ & $1.26 \pm 0.11$ & $0.02 \pm 0.00$ & $0.05 \pm 0.00$ & $0.17 \pm 0.03$ & $0.12 \pm 0.01$ & $1.23 \pm 0.04$ & \\
\hline P. major & Outdoors & $0.31 \pm 0.02$ & $0.31 \pm 0.02$ & $0.05 \pm 0.00$ & $0.23 \pm 0.02$ & $0.52 \pm 0.12$ & $0.02 \pm 0.00$ & $0.03 \pm 0.00$ & $0.09 \pm 0.01$ & $0.05 \pm 0.00$ & $1.20 \pm 0.10$ & \\
\hline P. major 'Rubrifolia' & Greenhouse & $0.99 \pm 0.21$ & $0.59 \pm 0.08$ & $0.19 \pm 0.02$ & $0.52 \pm 0.04$ & $2.70 \pm 0.23$ & $0.04 \pm 0.01$ & $0.05 \pm 0.02$ & $0.12 \pm 0.01$ & $0.12 \pm 0.01$ & $0.83 \pm 0.09$ & \\
\hline P. major 'Rubrifolia' & Outdoors & $0.41 \pm 0.05$ & $0.25 \pm 0.02$ & $0.08 \pm 0.01$ & $0.28 \pm 0.03$ & $0.78 \pm 0.11$ & $0.00 \pm 0.01$ & $0.05 \pm 0.00$ & $0.10 \pm 0.01$ & $0.09 \pm 0.02$ & $0.81 \pm 0.07$ & \\
\hline P. major 'Rosularis' & Greenhouse & $0.82 \pm 0.11$ & $0.55 \pm 0.04$ & $0.07 \pm 0.01$ & $0.36 \pm 0.03$ & $0.87 \pm 0.05$ & $0.01 \pm 0.01$ & $0.03 \pm 0.00$ & $0.09 \pm 0.00$ & $0.06 \pm 0.01$ & $0.84 \pm 0.05$ & \\
\hline P. major 'Rosularis' & Outdoors & $0.06 \pm 0.01$ & $0.12 \pm 0.01$ & $0.02 \pm 0.00$ & $0.07 \pm 0.01$ & $0.05 \pm 0.00$ & $0.00 \pm 0.00$ & $0.02 \pm 0.01$ & $0.05 \pm 0.00$ & $0.03 \pm 0.01$ & $0.24 \pm 0.01$ & \\
\hline P. lanceolata & Greenhouse & $0.64 \pm 0.14$ & $0.71 \pm 0.12$ & $0.08 \pm 0.02$ & $0.23 \pm 0.04$ & $0.35 \pm 0.08$ & $0.00 \pm 0.00$ & $0.04 \pm 0.01$ & $0.08 \pm 0.02$ & $0.12 \pm 0.02$ & $0.54 \pm 0.10$ & \\
\hline P. lanceolata & Outdoors & $0.05 \pm 0.01$ & $0.14 \pm 0.01$ & $0.01 \pm 0.00$ & $0.04 \pm 0.00$ & $0.01 \pm 0.00$ & $0.00 \pm 0.00$ & $0.02 \pm 0.00$ & $0.02 \pm 0.00$ & $0.01 \pm 0.00$ & $0.19 \pm 0.02$ & \\
\hline P. media & Greenhouse & $0.55 \pm 0.07$ & $0.69 \pm 0.10$ & $0.05 \pm 0.02$ & $0.21 \pm 0.03$ & $0.31 \pm 0.07$ & $0.00 \pm 0.00$ & $0.04 \pm 0.00$ & $0.07 \pm 0.02$ & $0.06 \pm 0.01$ & $0.66 \pm 0.10$ & \\
\hline P. media & Outdoors & $0.05 \pm 0.03$ & $0.13 \pm 0.05$ & $0.01 \pm 0.01$ & $0.04 \pm 0.03$ & $0.03 \pm 0.04$ & $0.00 \pm 0.01$ & $0.02 \pm 0.01$ & $0.02 \pm 0.01$ & $0.01 \pm 0.01$ & $0.32 \pm 0.07$ & \\
\hline P. major 'Frills' & Greenhouse & $1.35 \pm 0.28$ & $0.77 \pm 0.08$ & $0.09 \pm 0.01$ & $0.39 \pm 0.04$ & $0.76 \pm 0.09$ & $0.00 \pm 0.00$ & $0.05 \pm 0.00$ & $0.09 \pm 0.03$ & $0.06 \pm 0.01$ & $1.05 \pm 0.13$ & \\
\hline P. major 'Frills' & Outdoors & $0.05 \pm 0.01$ & $0.13 \pm 0.02$ & $0.01 \pm 0.00$ & $0.04 \pm 0.00$ & $0.03 \pm 0.00$ & $0.00 \pm 0.00$ & $0.02 \pm 0.00$ & $0.02 \pm 0.00$ & $0.01 \pm 0.00$ & $0.32 \pm 0.04$ & \\
\hline Species/varieties & $\begin{array}{c}\text { Growth } \\
\text { conditions }\end{array}$ & GABA & Tyr & Val & Met & HisNH2 & Phe & Ile & Leu & Lys & Tyramine & TOTAL \\
\hline P. major & Greenhouse & $0.95 \pm 0.06$ & $0.09 \pm 0.01$ & $0.12 \pm 0.01$ & $0.00 \pm 0.00$ & $0.51 \pm 0.04$ & $0.08 \pm 0.01$ & $0.11 \pm 0.01$ & $0.10 \pm 0.01$ & $0.09 \pm 0.01$ & $0.04 \pm 0.01$ & $8.66 \pm 0.64$ \\
\hline$P$. major & Outdoors & $0.94 \pm 0.07$ & $0.05 \pm 0.00$ & $0.09 \pm 0.01$ & $0.01 \pm 0.00$ & $0.65 \pm 0.06$ & $0.04 \pm 0.00$ & $0.05 \pm 0.00$ & $0.06 \pm 0.00$ & $0.07 \pm 0.00$ & $0.01 \pm 0.00$ & $4.79 \pm 0.45$ \\
\hline P. major 'Rubrifolia' & Greenhouse & $0.87 \pm 0.10$ & $0.06 \pm 0.01$ & $0.10 \pm 0.01$ & $0.01 \pm 0.00$ & $0.49 \pm 0.06$ & $0.05 \pm 0.01$ & $0.06 \pm 0.03$ & $0.08 \pm 0.01$ & $0.07 \pm 0.01$ & $0.01 \pm 0.00$ & $7.94 \pm 0.97$ \\
\hline P. major 'Rubrifolia' & Outdoors & $1.39 \pm 0.11$ & $0.08 \pm 0.01$ & $0.11 \pm 0.01$ & $0.00 \pm 0.01$ & $0.74 \pm 0.06$ & $0.07 \pm 0.01$ & $0.07 \pm 0.02$ & $0.10 \pm 0.02$ & $0.11 \pm 0.02$ & $0.02 \pm 0.01$ & $5.54 \pm 0.63$ \\
\hline P. major 'Rosularis' & Greenhouse & $0.75 \pm 0.04$ & $0.04 \pm 0.01$ & $0.07 \pm 0.01$ & $0.01 \pm 0.00$ & $0.46 \pm 0.04$ & $0.03 \pm 0.00$ & $0.05 \pm 0.00$ & $0.04 \pm 0.01$ & $0.05 \pm 0.01$ & $0.01 \pm 0.00$ & $5.22 \pm 0.42$ \\
\hline P. major 'Rosularis' & Outdoors & $0.60 \pm 0.04$ & $0.04 \pm 0.00$ & $0.06 \pm 0.00$ & $0.00 \pm 0.00$ & $0.32 \pm 0.01$ & $0.03 \pm 0.01$ & $0.05 \pm 0.00$ & $0.04 \pm 0.01$ & $0.05 \pm 0.00$ & $0.00 \pm 0.00$ & $1.85 \pm 0.14$ \\
\hline P. lanceolata & Greenhouse & $0.24 \pm 0.05$ & $0.05 \pm 0.01$ & $0.09 \pm 0.01$ & $0.00 \pm 0.00$ & $0.05 \pm 0.01$ & $0.06 \pm 0.01$ & $0.08 \pm 0.01$ & $0.08 \pm 0.01$ & $0.05 \pm 0.01$ & $0.00 \pm 0.00$ & $3.49 \pm 0.67$ \\
\hline P. lanceolata & Outdoors & $0.05 \pm 0.01$ & $0.02 \pm 0.00$ & $0.02 \pm 0.00$ & $0.01 \pm 0.01$ & $0.05 \pm 0.01$ & $0.02 \pm 0.00$ & $0.02 \pm 0.01$ & $0.02 \pm 0.00$ & $0.02 \pm 0.00$ & $0.01 \pm 0.00$ & $0.73 \pm 0.09$ \\
\hline P. media & Greenhouse & $0.33 \pm 0.08$ & $0.05 \pm 0.01$ & $0.07 \pm 0.02$ & $0.00 \pm 0.00$ & $0.04 \pm 0.01$ & $0.05 \pm 0.01$ & $0.07 \pm 0.01$ & $0.07 \pm 0.01$ & $0.06 \pm 0.01$ & $0.00 \pm 0.00$ & $3.36 \pm 0.57$ \\
\hline P. media & Outdoors & $0.12 \pm 0.05$ & $0.02 \pm 0.01$ & $0.03 \pm 0.01$ & $0.00 \pm 0.00$ & $0.09 \pm 0.04$ & $0.01 \pm 0.01$ & $0.02 \pm 0.01$ & $0.02 \pm 0.01$ & $0.02 \pm 0.01$ & $0.01 \pm 0.00$ & $0.97 \pm 0.43$ \\
\hline P. major 'Frills' & Greenhouse & $0.71 \pm 0.09$ & $0.05 \pm 0.01$ & $0.08 \pm 0.01$ & $0.00 \pm 0.00$ & $0.03 \pm 0.00$ & $0.04 \pm 0.00$ & $0.06 \pm 0.00$ & $0.05 \pm 0.01$ & $0.06 \pm 0.01$ & $0.00 \pm 0.00$ & $5.69 \pm 0.81$ \\
\hline P. major 'Frills' & Outdoors & $0.12 \pm 0.01$ & $0.02 \pm 0.00$ & $0.03 \pm 0.00$ & $0.00 \pm 0.00$ & $0.09 \pm 0.01$ & $0.01 \pm 0.00$ & $0.02 \pm 0.00$ & $0.02 \pm 0.00$ & $0.02 \pm 0.00$ & $0.01 \pm 0.00$ & $0.98 \pm 0.12$ \\
\hline
\end{tabular}




\section{DISCUSSION}

It is well known that environmental factors, such as exposure to sunlight, temperature, wind, water/moisture and soil composition can influence the presence and content of natural compounds in plants.

UV-absorbing phenolic compounds, such as flavonoids are particularly important for plants to protect their vegetative organs from harmful UV radiation from the sun (Murai et al., 2009). Both plantamajoside and verbascoside were found in the leaves of $P$. asiatica in Mt. Norikura in Japan (Murai et al., 2009). Verbascoside was not detected in plants at low altitude, where the intensity of UV radiation is lower that at higher elevations. This is in agreement with the results of the present study where lower contents of all BCAD were found in plants grown in the greenhouse, where UV radiation is low compared with outdoors. The UV absorbing aspect is directly correlated to the antioxidative activity of the compounds and the antioxidant activity of verbascoside is potentially stronger than that of plantamajoside (Nishibe, 2002). Other studies of this nature have been described for Plantago spp. under different environmental conditions. The top DW and content of verbascoside were greater for $P$. lanceolata grown at $15{ }^{\circ} \mathrm{C} / 10{ }^{\circ} \mathrm{C}$ day/night temperature compared with $20{ }^{\circ} \mathrm{C} / 18 \quad{ }^{\circ} \mathrm{C}$ day/night temperature (Tamura et al., 2001). Plants grown under shading had a lower number of leaves per plant, top dry matter weight and top dry matter content, though they were greater in height. The content of verbascoside was significantly lower in plants grown in the shade.

In any growing season, UV exposure and other environmental factors have an influence on the composition and content of the BCAD and amino acids. In two cultivars of $P$. lanceolata, verbascoside concentration increased from 3.4 to $7.1 \%$ in Grassland Lancelot cultivar and from 1.5 to $4.1 \%$ in Ceres Tonic cultivar over the course of the growing season after which concentrations declined steadily to $2.5 \%$ in Grassland and $1.9 \%$ in Ceres Tonic (Tamura and Nishibe in
2002). These data suggested that mid-autumn was an appropriate time to harvest plantain for medical use by ensuring a greater concentration of verbascoside.

The concentration of bioactive compounds steadily decreased in the initial stages of drying both under natural climate conditions and at $60{ }^{\circ} \mathrm{C}$. In our study, all the Plantago plants were sown and harvested at the same time and once only during the season for both the greenhouse and the outdoor cultivated plants. However, it would be useful to study the effect of greenhouse and outdoor growing conditions throughout the growing season as the differences in content of BCAD and amino acids between the greenhouse and outdoor grown plants may vary during the growing period.

Nitrogen application enhanced the growth of $P$. lanceolata cultivars, especially the top fresh weight and it significantly diminished the top dry-matter content. The amount of verbascoside was apparently lower in the plants treated with nitrogen as opposed to non-fertilized plants and shade repressed the growth and accumulation of both compounds (Tamura, 2001).

The genetic composition of $P$. major is an important determinant for the composition of plantamajoside and verbascoside in the plants. The composition of three BCAD in the different Plantago species was genetically determined (Mølgaard, 1986), who observed that plantamajoside was found in both $P$. major subsp. major and $P$. major subsp. pleiosperma, but verbascoside was only found in P. major subsp. pleiosperma. The synthesis of caffeic acid esters is determined by a single gene with complete dominance for production of caffeoyl glucose, as found in plantamajoside (Mølgaard et al., 1980), although some population samples may indicate the genetics may be more complex (Mølgaard, 1986; Rohilla et al., 2012a,b).

Histochemical analysis and the HPTLC methods complement each other perfectly. The former can provide qualitative analysis and locate the BCAD compounds visually, both with and without reagents in the different plant cells and HPTLC can be used both for 
qualitative visual detection of compounds with or without reagent and quantification by separating the BCAD chromatographically into plantamajoside, iso-plantamajoside and verbascoside.

There are a few reported studies on the determination of individual FAA in Plantago, for example, Mohamed et al. (2011) reported the amino acid profile of $P$. major. Sagisaka et al., (1988) described the role of amino acids and inorganic ions in osmoregulatory responses of Plantago japonica L. and another study investigated the effect of fungicide treatment on the amino acid content of $P$. lanceolata leaves (Grange and West, 1994). Two studies were also carried out on the amino acid content of Plantago ovato (Romero-Baranzini et al., 2006). The content of FAA determined in this study is distinguished from previous reports, since experiments were carried out on protein hydrolysates (Romero-Baranzini et al., 2006). None of the previous studies investigated the effect of environmental conditions on the amino acid content in these Plantago species. However, it is interesting to note that in these studies the most abundant amino acids were glutamate, aspartate, glutamine, asparagine and alanine, as was the case in the present study.

There are reports on the effect of solar radiation on the production of mycosporinelike amino acids in several species. Research has shown that UVB/UVA exclusion in the field reduced nitrate reductase (NR) activity in leaves of silver birch seedlings (Krywult et al., 2002). It was confirmed by other observations that enhanced UVB inhibits growth and reduces NR activity in dragon spruce needles (Yao and Liu, 2007) and in young crop seedlings (Rajendiran and Ramanujam, 2006). Nitrate reductase is a key enzyme of $\mathrm{N}$ metabolism, which converts nitrate into nitrite in the metabolic pathway leading to the formation of amino acids (Canovas et al., 2007).

Of particular interest to the present paper is a study in 2006 on the influence of solar radiation on NR and the amino acid content of Scots pine needles in subarctic ecosystems (Krywult et al., 2008). It was found that the exclusion of both UVA et UVB light lead to an increase in the amino acid content of the pine needles, an increase that the authors attributed to a lower demand for stress proteins and/or a higher demand for enzyme proteins involved in the saplings' antioxidant scavenging metabolism, given that UV stress is known to generate reactive oxygen species (Turunen and Latola, 2005). The present study also found that amino acid content in outdoor grown plants was significantly lower than in the same plants cultivated under identical conditions in the greenhouse. This has never before been observed in Plantago species, but these findings confirm the observation of Krywult et al. (2008), although it should be stressed that they did not report the effects on individual amino acids.

Aromatic amino acids such as phenylalanine and tyramine are important intermediates for the biosynthesis and production of the BCAD. They are involved in the shikimic acid biosynthesis of aromatic caffeoyl esters (Abe et al., 2002) and therefore there is a strong relationship between the two groups of compounds. However, the contents of the BCAD are much higher than the amino acids in all the Plantago spp., and especially the aromatic FAA. The FAA, are the products of primary metabolism, are primary metabolites, whereas BCAD are secondary metabolites, often produced as a reaction to stress in plants. It is interesting to note that results in this study clearly demonstrated that BCAD concentrations in plants grown outdoors were significantly greater than those in greenhouse grown plants, whereas the converse was true for FAA. The results of this study underline the importance of looking into more than one group of compounds when environmental studies are performed.

Furthermore a comparative study demonstrating environmental effects on BCAD and amino acids simultaneously has not previously been reported for Plantago species. Since the BCAD are important natural compounds, outdoor grown plants with greater amounts of plantamajoside, iso- 
plantamajoside and verbascoside would be preferred for the production of Plantago and other plants used for their medicinal properties.

\section{Conclusion}

The content of bioactive compounds in plants change with respect to growth conditions. Plantago plants grown outdoors were significantly richer in BCAD compared with greenhouse grown plants where UV radiation is lower. In contrast FAA concentrations were significantly richer for greenhouse grown plants. Histochemical analysis clearly illustrated major differences in leaf texture; notably in the plants grown outdoors the BCAD were present at high concentrations in almost all mesophyll cells, but were only detected in some palisade parenchyma in the greenhouse grown plants. This study underlined the importance of growing conditions for plants in order to obtain high concentrations of bioactive compounds either from a nutritional point of view or for the anti-inflammatory properties of BCAD in natural medicine. It also highlights the importance of environmental conditions from an agricultural perspective where plants are used as a food source.

\section{ACKNOWLEDGEMENTS}

We thank I.-L. Lauridsen and C. Jensen for growing the plants and preparing the plant material for analysis. A special thanks to T. Meadows for performing the HPLC analysis of the amino acids. We also thank Aarhus University and University of Montpellier for supporting this work though the interuniversity collaboration agreements. A special thanks to Julie von Müllers Fund for support of a research stay for H.W. Ravn in Montpellier.

\section{AUTHORS CONTRIBUTIONS}

HPTLC analyses were carried out by HWR, histochemistry by LM, amino acid analysis by MTK and statistical tests and analysis by AML. All authors contributed to writing and editing.

\section{REFERENCES}

Abe F, Nagoa T, Okabe H. 2002. Antiproliferative constituents in plants 9. Aerial parts of Lippia dulcis and Lippia canescens. Biol. Pharm. Bull., 25(7): 920-922.

Adjagba M, Awede B, Osseni R, Hountondji C, Dougnon G, Lagnika L, Darboux R, Laleye A. 2017. Antihypertensive effect of extracts from Crateva adansonii DC. ssp. adansonii in the Wistar rats. Int. J. Biol. Chem. Sci., 11(6): 2604-2615. DOI: 10.4314/ijbcs.v11i6.5.

Amakura Y, Yoshimura A, Yoshimura M, Yoshida T. 2012. Isolation and characterization of phenolic antioxidants from Plantago herb. Molecules, 17(5): 5459-5466. DOI: $10.3390 /$ molecules17055459.

Byamukama R, Barbara G, Namukobe J, Heydenreich M, Kiremire BT. 2015. Bioactive compounds in the stem bark of Albizia coriaria (Welw. ex Oliver). Int. J. Biol. Chem. Sci., 9(2): 1013-1024. DOI: $10.4314 /$ ijbcs.v9i2.37.

Canovas FM, Avila C, Canton FR, Canas RA, de la Torre F. 2007. Ammonium assimilation and amino acid metabolism in conifers. J. Exp. Bot., 58: 2307-2318. DOI: doi.org/10.1093/jxb/erm051.

Gonda S, Nguyen NM, Batta G, Gyemant G, Mathe C, Vasas G. 2013. Determination of phenylethanoid glycosides and iridoid glycosides from therapeutically used Plantago species by CE-MEKC. Electrophoresis, 34(17): 2577-2584.

Grange AC, West HM. 1994. Interactions between arbuscular mycorrhizal fungi and foliar-feeding insects in Plantago lanceolata L. New Phytol., 128: 79-87.

Hjorth M, Mathiassen SK, Kudsk P, Ravn HW. 2006. Amino acids in loose silkybent Apera spica-venti L. Beauv. responding to prosulfocarb exposure and the correlation with physiological 
effects. Pest. Biochem. Phys., 86: 138145.

Jdey A, Falleh H, Ben Jannet S, Hammi K Mkadmini, Dauvergne X, Ksouri R, Magne C. 2017. Phytochemical investigation and antioxidant, antibacterial and anti-tyrosinase performances of six medical halophytes. S. Afr. J. Bot., 112: 508-514.

Kelly MT, Larroque M. 2010. Rapid automated high performance liquid chromatography method for simultaneous determination of amino acids and biogenic amines in wine, fruit and honey. J. Chromatogr. A, 1217: 7385-7392.

DOI: 10.1016/j.chroma.2010.09.047.

Krywult M, Turunen M, Sutinen M-L, Derome K, Norokorpi Y. 2002. Nitrate reductase activity in some subarctic species and UV influence in the foliage of Betula pendula Roth. seedlings. Sci. Total. Environ., 284(1-3): 149-155. DOI: 10.1016/S0048-9697(01)00875-0.

Krywult M, Smykl J, Kinnunen H, Martz F, Sutinen M-L, Lakkala K, Turunen M. 2008. Influence of solar UV radiation on the nitrogen metabolism in needles of Scots pine Pinus sylvestris L. Environ. Pollut., 156: 1105-1111. DOI: 10.1016/j.envpol.2008.04.009.

Kyokai NK. 1986. Japanese Pharmacopeia XI. Hirokawa: Tokyo. 439.

Mohamed IK, Osama MA-F Samiha MAE-S, Zahrat E-OMM. 2011. Biochemical studies on Plantago major L. and Cyamopsis tetragonoloba L., Int. J. Biodivers., 3(3): 83-91.

Mondolot-Cosson L, Andary C, Guang-Hui D, Roussel J-L. 1997. Histolocalisation de substances phénoliques intervenant lors d'interactions plante-pathogène chez le Tournesol et la Vigne. Acta Botanica Gallica, 144: 353-362. DOI: 10.1080/12538078.1997.10515380.
Murai Y, Taemura S, Takeda K, Kitajima J. 2009. Altitude variation of UVabsorbing compounds in Plantago asiatica. Biochem. Syst. Ecol., 37(4): 378-384. DOI: $10.1016 /$ j.bse.2009.07.005.

Mølgaard P, Skjøth L, Kaufmann U. 1980. A genetic investigation of esters of caffeic acid with rhamnose or glucose in leaves of Plantago major. Biochem. Syst. Ecol., 8: $277-278$.

Mølgaard P. 1986. Population genetics and geographical distribution of caffeic acid esters in leaves of Plantago major in Denmark. J. Ecol., 74: 1127-1137.

Nishibe S. 2002. The plant origins of herbal medicines and their quality evaluation. Kuga Zasshi, 122: 363-379.

Ogbiko C, Eboka CJ, Tambuwal AD. 2018. Extraction and fractionation of whole black seed Plantain (Plantago rugelii Decne) for in-vitro antioxidant, antibacterial and phytochemical screening. J. Appl. Sci. Environ. Manage., 22(5): 613-618. DOI: 104314/jasem.v22i5.1.

Ogwuche CE, Amupitan JO, Ndukwe GI. 2015. Antimicrobial activity of the leaf of the white species of Sesamum indicum from Benue State, Nigeria. Int. J. Biol. Chem. Sci., 9(2): 996-1003. DOI: 10.4314/ijbcs.v9i2.35.

Olennikov DN, Tankhaeva LM, Stolbikova AV, Petrov EV. 2011. Phenylpropanoids and polysaccharides from Plantago depressa and $P$. media growing in Buryatia. Chem. Nat. Comp., 47(2): 165169.

Rajendiran K, Ramanujam MP. 2006. Interactive effects of UV-B irradiation and triadimefon on nodulation and nitrogen metabolism in Vigna radiata plants. Biol. Plantarum, 50(4): 709-712. DOI: 10.1007/s10535-006-0112-3.

Ravn H, Brimer L. 1988. Structure and antibacterial activity of plantamajoside, a 
caffeic acid sugar ester from Plantago major subsp. major. Phytochemistry, 27(11): 3433-3437. DOI: 10.1016/00319422(88)80744-1.

Ravn HW, Mondolot L, Kelly MT, Lykke AM. 2015. Plantamajoside - A current review. Phytochem. Lett., 12: 42-53. DOI: 10.1016/j.phytol.2015.02.002.

Rohilla AK, Kumar M, Sindhu A, Boora KS. 2012a. Genetic diversity analysis of the medicinal herb Plantago ovata (Forsk.). Afr. J. Biotechnol., 11(86): 15206-15213. DOI: 10.5897/AJB12.681.

Rohilla AK, Kumar M, Sindhu A, Boora KS. 2012b. Genetic diversity analysis of the medicinal herb Plantago ovata (Forsk.). Afr. J. Biotechnol., 11(92): 15835-15842. DOI: $10.5897 / A J B 12.681$

Romero-Baranzini AL, Rodriguez OG, Yanez-Farias GA, Barron-Hoyos JM, Rayas-Duarte P. 2006. Chemical, physicochemical and nutritional evaluation of Plantago ovata Forsk. Cereal Chem., 83(4): 358-362.

Sagisaka S, Ohwada T, Akari T. 1988. The role of amino acids and inorganic ions in osmoregulatory responses of Plantago japonica Franch. et Sav. Agric. Biol. Chem., 52: 321- 328.
Sawadogo S, Sanou SD, Dabire P, Belemtougri GR, Sawadogo L, Leiris J de, Tanguy S, Boucher F. 2017. Activité antifalcémiante d'extraits de trois plantes médicinales du Bukina Faso: Jatropha curcas, Khaya senegalensis et Dichrostachys cinerea. Int. J. Biol. Chem. Sci., 11(5): 2016-2027. DOI: 10.4314/ijbcs.v11i5.7.

Tamura Y. 2001. Effects of temperature, shade, and nitrogen application on the growth and accumulation of bioactive compounds in cultivars of Plantago lanceolata L. Jpn. J. Crop Sci., 70(4): 548-553.

Tamura Y, Nishibe S. 2002. Changes in the concentration of bioactive compounds in plantain leaves. J. Agric. Food Chem., 50(9): 2514-2518.

Turunen M, Latola K. 2005. UV-B radiation and acclimation in timberline plants. Environ. Pollut., 137(3): 390-403. DOI: 10.1016/j.envpol.2005.01.030.

Yao X, Liu Q. 2007. Responses in growth, physiology and nitrogen nutrition of dragon spruce Picea asperata seedlings of different ages to enhanced ultravioletB. Acta Physiol. Plant., 29(3): 217-224. DOI: $\quad 10.1007 / \mathrm{s} 11738-007-0027-4$. 